\title{
Graduate Program in Pharmacology and Experimental Therapeutics - A Joint Endeavor of the University of Cologne and Bayer Schering
}

\author{
Stefan Herzig ${ }^{*}, 1$, Marion Rozowski ${ }^{1}$ and Ingo Flamme ${ }^{2}$ \\ ${ }^{I}$ Department of Pharmacology, University of Cologne, Gleueler Strasse 24, 50931 Köln, Germany \\ ${ }^{2}$ Bayer Health Care AG, Pharma Research, 42096 Wuppertal, Germany
}

\begin{abstract}
In 2008, the University of Cologne and Bayer Schering Pharma together decided to establish a "privileged partnership" in order to foster interactions in the field of preclinical and clinical drug discovery and development. As one of the activities of this partnership, we launched a graduate program run by the University and supported by Bayer funds. Founded in 2009, the program now provides administrative and personal support as well as a scientific curriculum for 16 students. They carry out their doctoral thesis (PhD or MD) work either at a research lab at Bayer, or at the Medical or the Natural Sciences Faculty of the University. Research topics span the field of shared scientific interests of the partners (e.g., cardiovascular diseases, acute care, oncology). Project selection, student recruitment, and curriculum design are carried out by a program committee, which equally represents Bayer and the two participating University Faculties. Within a 2- or 3-year curriculum, students meet regularly for journal clubs, soft-skills workshops, and special courses. They carry out a lab rotation over several weeks at the partner institution - students working at the university are then hosted in a lab at Bayer and vice versa. Students receive scientific and personal support from their thesis committee (supervisor plus two mentors, again representing both Faculties and Bayer).

Feedback from students, principal investigators and external reviewers indicates that an environment combining partners from academia and industry is highly appreciated and carries the potential to attract particularly gifted students. Compared with other, publicly funded graduate programs in Germany, the research topics within our program are rather diverse, which require that a common thread of important aspects of pharmacology is implemented within the core curriculum. Ultimately, our program will be evaluated with regard to academic output and career opportunities for its graduates.
\end{abstract}

Keywords: Academia-industry partnership, drug discovery, experimental therapeutics, graduate program, pharmacology, postgraduate education.

\section{INTRODUCTION}

The future of innovative medical therapy, along with the economic fate of pharmaceutical companies is being challenged by a constant decline in the development of new drugs and chemical entities [1]. At the same time, although modern pharmacology has the potential to broaden its scope into all fields of modern life sciences [2], broadly trained pharmacologists are in short supply [3]. Given this situation, universities and the pharmaceutical industry appear as natural partners in helping to bridge the gap between academic research and modern drug development. Indeed, first initiatives for joining forces to improve graduate level education in pharmacology date back more than 20 years (e.g. [4, 5]). However, the large majority of academia/ industry collaborations have been of short duration and small scale [6]. Although the number of graduate programs in pharmacology within universities increases steadily [7], the main focus of academia/pharmaceutical industry collaborations is seen in research and development $[8,9]$ rather than education, where the unique strength of academic institutions lies [10]. Goal-oriented, structured postgraduate education appears valuable, including settings that are partially

*Address correspondence to this author at the Department of Pharmacology, University of Cologne, Gleueler Strasse 24, 50931 Köln, Germany; Tel: +29 221478 6064; Fax: +49 221 89049; E-mail: Stefan.herzig @uni-koeln.de supported by industrial partners [11]. Little is known about the structure, process and outcome of such academia/ industry partnerships primarily devoted to pharmacology education. Hence, here we describe our first experiences with a novel graduate program, founded and operated collaboratively by Bayer Schering Pharma and the University of Cologne to educate future pharmacologists under the umbrella of a "privileged public-private partnership" between the two institutions.

\section{BACKGROUND AND HISTORY}

North Rhine Westphalia is the largest federal state of Germany regarding population size. Within a $50 \mathrm{~km}$ circumference of Cologne, four universities maintaining medical schools, and two offering Pharmacy degrees are situated. In addition, there is a remarkable number of small, medium and large-size pharmaceutical and biotech companies, including a main research facility of Bayer Schering Pharma in Wuppertal. Also, the federal drug regulatory agency is located in the neighborhood city of Bonn.

In the 1990s German Universities came under pressure from the government as well as from the systematic evaluation through the German Research Council (Wissenschaftsrat). In particular, the University of Cologne Medical Faculty was encouraged to more strongly focus on a limited number of core areas of research. We decided to 
focus our efforts by concentrating on research in the fields of cardiovascular disease, infection and defense, tumor biology and molecular neuroscience. The area of ageing and metabolism emerged later on. In the same period along with the fusion process of Bayer and Schering Pharma, the resulting company also had to undertake a major remodeling of their areas of research and development interest. At the present time, areas of interest to Bayer Schering Pharma are cardiology (including hematology and acute care), oncology, diagnostic imaging and women's health care. There is an obvious match in at least two areas of research between Bayer Schering Pharma and the Medical Faculty of the University of Cologne. This fact, besides the geographical proximity had enabled a number of independent bilateral project collaborations both in basic biomedical research and in clinical studies in the past. Close contacts between individual researchers involved in those collaborations led to the idea of a privileged partnership, intended to strengthen the ties between Bayer Schering Pharma and the University of Cologne in fundamental research and with respect to the clinical development of novel pharmacological agents.

Early in 2008, a roadmap for a privileged partnership was defined by the respective upper managements. The first and main goal of this partnership was to foster the collaboration in the area of clinical studies of all phases. As a second and novel goal, the idea of a joint graduate program, intended to educate future pharmacologists was conceived. We were asked to conceptualize a blueprint for such a graduate program. By the middle of the year 2008 we presented that blueprint together with the proposals resulting from the first project call and their scientific evaluation. In December 2008 a first recruitment round of PhD-Students could be completed and the partnership contract was signed, allowing for a first funding period to start in 2009. The first external evaluation took place in November 2010. The evaluation report will inform the decisions whether and how the support for the program will be continued for another three-year period.

\section{ORGANIZATIONAL STRUCTURE, RESEARCH TOPICS AND EDUCATIONAL PROGRAM}

The program blueprint was written in strict analogy to the usual grant application format used by similar programs funded by the German Research Foundation (DFG) [12]. In addition, it took into account the aims and funding options of the pharmaceutical industry partner. The stakeholders from both sides phrased a mission statement (Table 1). In order to identify research areas and individual projects which could best fulfill these goals, we invited scientists from the Medical and Science Faculties and from Bayer to brainstorm and define which of their individual research areas and methods would meet the interests of both partners and could be used to recruit high-quality scientific projects. Using a two-step Delphi process, ideas were first collected, then clustered and rearranged according to their suitability and coherence. By this procedure, we were able to define "acute care, defense and sepsis", "cardiology, kidney and vasculature", "neuroscience" and "oncology" as primary research areas. Projects should preferably involve disease models (mice), large animals models, in vivo imaging, telemetry, or identification of biomarkers as part of their methodology.

\section{Table 1. Mission Statement of the Graduate Program}

"Innovative drug research has been largely driven by target-oriented high-throughput screening approaches in the last decade. Despite remarkable examples of success, the overall rate of innovative drugs introduced has dropped by half in this period. At the same time, scientific expertise in some typical areas of pharmacology such as whole-animal research and systems physiology has vanished, due to retirement of researchers trained during the period of successful classical pharmacology. Our program is intended as an enterprise to reestablish a continuum of modern, i.e. molecular-based drug discovery, from cell to systems-based pharmacological research and hypothesisdriven clinical testing of new therapeutic principles. It shall thereby develop and validate a prototypical strategy to establish a translational research framework incorporating all the academic and industrial knowledge, skills and facilities needed for future therapeutic innovations. Its graduates, besides their training on-the-project, will receive a systematic, structured educational program aimed to support specific laboratory as well as generic "soft" skills for their science. This program will widen the scope of research along the translational continuum, provide individual mentoring and an introduction to international scientific role models, and finally foster exchange between academic and industry-based lab environments. With respect to research topics, the focus will be set on overlapping fields of interest and excellence of both the Medical Faculty of the University of Cologne and of BAYER: Molecular and Clinical Cardiovascular Science, Neuroscience, Oncology and Defense. Methods of special interest are the development and characterization of disease-relevant animal models by modern molecular genetics, imaging, biochemical and physiological techniques, including in vivo instrumentation and electrophysiological recording. Early clinical trials may also be incorporated if helpful to address a timely basic research question."

In order to comply with the University regulations concerning the issuing of doctoral degrees, our graduate program is embedded into an umbrella organization within the University, the Graduate School for Biological Sciences (GSfBS) [13]. Several PhD programs are integrated into this graduate school, including those arising from collaborative research groups funded by the DFG, or those of the MaxPlanck-Institutes located in Cologne, or programs resulting from collaborations between the Medical and Science Faculty (MD/PhD program, Cluster of Excellence program). The graduate school offers organizational help by providing a regulatory framework for recruitment and student support, as well as some curricular elements for all students, like softskills courses, or the provision of a fast track masters program.

Our program is characterized by a systematically shared responsibility regarding organizational aspects between three partners, namely Bayer Schering Pharma, the Medical Faculty within the University Hospital and the Science Faculty of the University of Cologne. The board of all principal investigators from the three institutions constitutes the "program council", which elects the speaker and further members of a "program committee". The program committee has the obligation to evaluate proposals and select projects, to identify suitable mentors for the students, and to supervise the curriculum as organized by a program office, 
Table 2. Enrolled Projects by Area, Investigator(s), Affiliation and Title

\begin{tabular}{|c|c|c|}
\hline \multicolumn{3}{|c|}{ A: Acute Care, Defense } \\
\hline A03 & Brachvogel (Biochemistry) & Identification of novel biomarkers to target apoptotic cells in vivo \\
\hline A04 & Flamme (Bayer) & Adrenomedullin: Regulator of the endothelial barrier \\
\hline A06 & Heitmeier (Bayer) & The role of fibrin in organ damage in DIC \\
\hline \multicolumn{3}{|c|}{ C: Cardiovascular Science } \\
\hline $\mathrm{C} 03$ & Herzig (Pharmacology) & $\begin{array}{l}\text { Pathophysiological role of RGK family G-proteins in molecular and functional calcium channel } \\
\text { remodeling in heart failure }\end{array}$ \\
\hline $\mathrm{C} 04$ & Pfitzer (Physiology) & $\begin{array}{l}\text { Effects of FHC-associated mutations of troponin on its } \mathrm{Ca}^{2+} \text {-induced conformational change and } \\
\text { on the } \mathrm{Ca}^{2+} \text {-transients of cardiomyocytes }\end{array}$ \\
\hline $\mathrm{C} 05$ & Trübel (Bayer) & $\begin{array}{l}\text { Role of myosin light chain phosphatase (MLCP) variants in etiopathologicaly distinct forms of } \\
\text { pulmonary hypertension }\end{array}$ \\
\hline $\mathrm{C} 07$ & Rosenkranz (Cardiology) & PI 3-kinase as a central therapeutic target in pulmonary hypertension \\
\hline $\mathrm{C} 06$ & Benzing Schermer (Nephrology) & $\begin{array}{l}\text { Function of the glomerular microcirculation and filtration barrier and the pathogenesis of } \\
\text { proteinuric kidney diseases and hypertension }\end{array}$ \\
\hline $\mathrm{C} 09$ & Stasch (Bayer) & Nitric oxide-independent activation of the soluble guanylate cyclase \\
\hline $\mathrm{C} 12$ & Liakopoulos Choi (Cardiac Surgery) & $\begin{array}{l}\text { Pharmacological cardioprotection by activation of the soluble guanylate cyclase by BAY 58- } \\
2667 \text { (Cinaciguat) }\end{array}$ \\
\hline $\mathrm{C} 13$ & Gründemann (Pharmacology) & Identification of the function of the transporter SLCO5A1 in rat and human \\
\hline
\end{tabular}

\section{$\mathrm{N}$ : Neuroscience}

\begin{tabular}{|l|l|l}
\hline N04 & Krone Schubert (Endocrinology) & Role of IGF-1 receptor signalling for amyloid precursor protein processing \\
\hline N08 & Plomann (Biochemistry) & Functional characterization of PACSIN 2-receptor/ion channel complexes in brain and heart \\
\hline N09 & Krone Schubert (Endokrinology) & Foxo expression in the aging murine brain \\
\hline N11 & Büschges (Zoology) & $\begin{array}{l}\text { Adaptation of chordotonal organ receptor types and the mode of action of insecticides on } \\
\text { scolopidial sensory neurons }\end{array}$ \\
\hline
\end{tabular}

\section{O: Oncology}

\begin{tabular}{|l|l|l|}
\hline O03 & Abken (Oncology) & Signal induced production of therapeuticals in vivo by T-cells with recombinant T-cell receptors \\
\hline O04 & Herling Hallek (Oncology) & Therapeutic targeting of anti-apoptotic pathways in chronic lymphocytic leukemia \\
\hline O08 & Hahnen (Genetics) & $\begin{array}{l}\text { Identification of relevant histone deacetylases for the pharmacological therapy of malignant } \\
\text { glioma }\end{array}$ \\
\hline O10 & Krause Hallek (Oncology) & Preclinical investigations regarding targeted therapies for chronic lymphocytic leukemia (CLL) \\
\hline
\end{tabular}


run by an academic professional working part-time. Each student has - in addition to their supervisor - at least two mentors from the two other partner institutions with whom to meet regularly. In every single case, a thesis committee is composed of members of the University Hospital, the Science Faculty and Bayer.

In total 35 scientific projects have been submitted, following two calls issued in 2008 (23) and 2009 (9), and thereafter as requests to join the program (3). They were evaluated according to scientific quality, the academic and educational track record of the PIs, and the match of the suggested project with the previously defined areas of research. Project proposals were received in nearly equal numbers in all four areas of research, both when counted at the submission stage (not shown) and when looking at the accepted projects (Table 2). Overall the acceptance rate was at about $50 \%$. Analysis of the topics of individual projects reveals that - even within a given research area, the program is thematically rather diverse. The majority of the projects deal primarily with disease mechanisms or the characterization of potential new drug targets. Up till now, a small number of projects involve the investigation of particular (classes of) chemical compounds, including their further development in terms of a primarily pharmacological, and less so medicinal chemistry approach.

To recruit PhD-Students, advertisements were placed in various online and print media in autumn 2008. This led to 70 applications from all over the world. All applications had to be submitted in a standard form, including a statement which project the applicant preferred among the projects offered within the program. Applications were first evaluated by members of the (initially ad hoc, later formally elected) program committee. Based on a first ranking, the top candidates were contacted by telephone especially when living overseas. We conducted one or two independent, structured telephone interviews of $30 \mathrm{~min}$. When the evaluation of the candidates after the telephone interview was positive (7 out of 10 in case of the overseas students), they were invited like the local top-ranking candidates for a personal interview to Cologne. Invited candidates had to give a 10-min scientific presentation (preferably on their own master or diploma thesis), followed by a 30-min interview with designated principal investigators, including at least three members of the program committee.

Through this selection procedure, we have by now recruited 18 students, four of which come from overseas. The strong gender bias in the program (14/18 females at recruitment) is - as we believe - primarily a consequence of a geographical bias (in applicant quality?), since most of our foreign applicants - the majority being male - , were not accepted into the program. Up to now, two of our 18 students (one male from overseas) decided to drop their thesis work and quit the program. The statistics of student enrollment (Fig. 1) show that with respect to the two funding periods starting January 2009 and January 2010, students were recruited with a time lag of 0 to 6 months. Currently, 16 students are actively involved. Enrolled students come from a variety of academic backgrounds. 6 of them hold diploma degrees in biology, 3 are licensed pharmacists and two are medical students at their clinical stage. All of the international students and some of our local students hold
Bachelor and Master degrees in various fields of biomedical science, such as neuroscience or molecular biotechnology. 12 of the included active projects are located within the Medical Faculty of the University of Cologne, three are situated at the Bayer Pharma Research Center in Wuppertal, and one in the Science Faculty at the University of Cologne. Bayer supports 6 of our students directly by paying their salary. The medical faculty pays a smaller stipend to two other students. All other projects are entirely funded by grant money of their principal investigators. In addition to the salaries, Bayer money funds our program coordinator, covers administrative costs and sponsors all the educational activities which are described below.

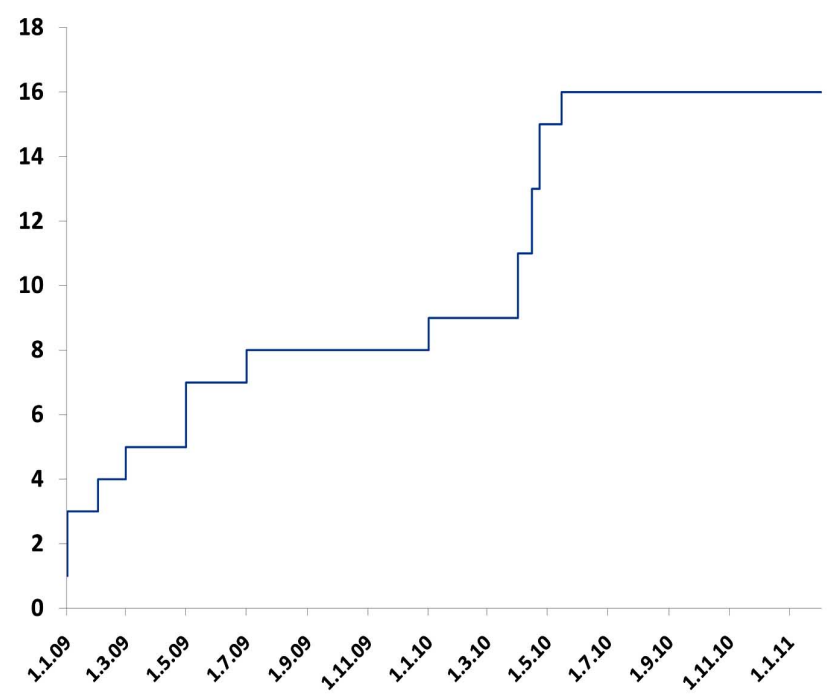

Fig. (1). Student enrollment over time.

Our students' curriculum requires written reports to be submitted as a 3-month-proposal, as a report after two years of research activity, and as a final dissertation before taking the graduation exam. Other educational activities include soft skills workshops. Courses on project management, animal experimentation and research ethics were introduced specifically for our program. All students within the program meet at least monthly for a journal club, commonly attended by several principal investigators. This occasion also serves to present progress reports and to invite guest speakers. Every student has to spend a 4-6 week lab rotation at the respective partner institution. Once a year students and principal investigators meet for two days to hold an annual retreat. Students are engaged in additional educational activities such as conferences or lecture series which they can use to gain credit for our total curricular requirement of 30 ECTS, which corresponds to a total workload of approximately 900 hours. This workload leads to occasional complaints, especially from students whose peers in their lab are not enrolled in any other structured doctoral program. However, as illustrated in Fig. (2), most of our students records are well within or above the range of interim expectation (9 ECTS after 1 year, 22 ECTS after 2 years).

To provide some first qualitative insight into the educational outcome, student comments taken from the regularly collected feedback questionnaires are given below. Statements from three students who are doing their Ph.D. 


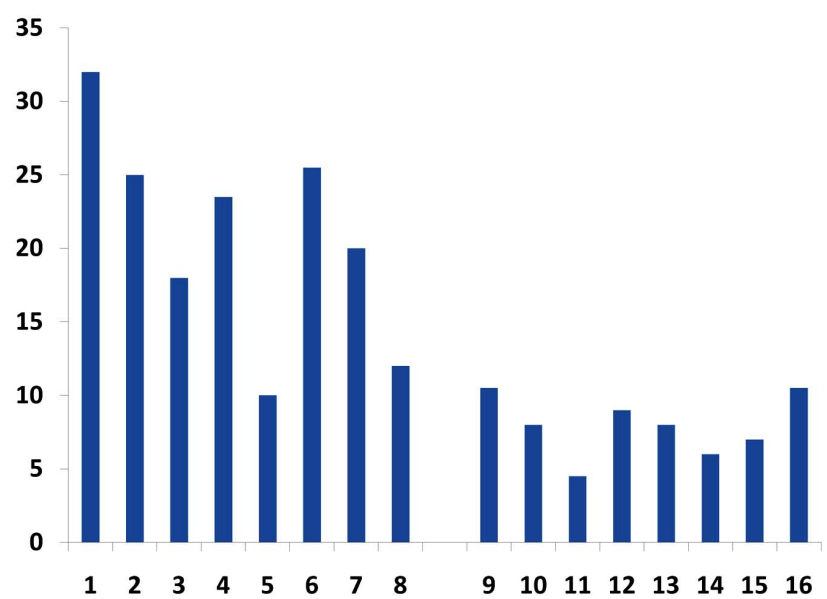

Fig. (2). Curriculum $(\mathrm{ECTS}=30 \mathrm{~h})$ of $2^{\text {nd }}(1-8)$ and $1^{\text {st }}$ year $(9-16)$ students.

work at the university after they spent their lab rotation at the Bayer site:

"They all explained well what and how they are doing the experiments in order to find new targets for pharmaceuticals. They seemed to be happy to be able to give their knowledge ...

....In general it was also very interesting to see in which research areas Bayer is doing its research - to get an impression if the field one is working in university somehow relates to the research in industry."

"....I was able to gain an understanding of how the industry operates. Several conversations with lab heads touched on differences between academia and industry, and I was struck by the impression that many people seemed to think that academic work is somehow not as rigorous."

"We planned a little project and I had the chance to send my own transgenic mice to Bayer. Therefore I recommend everyone to take some time before the internship starts".

Although it is too early to analyze the academic outcome of our future graduates, the chart of (co-)authorships of original publications in peer-reviewed journals (Fig. 3) illustrates that our students already contributed significantly to remarkable publications during the first two years of their PhD work. These publications indicate that many of the graduates are productively integrated into the research of their labs at an early stage of their thesis work. It also shows that team work is an important feature of their host labs.

Principal investigators were also prompted to give us written feedback from their perspective. Here are some examples:

"I realized how much the board meetings and organizational support had facilitated these important decisions and procedures (the selection of candidates).... The program has a high potential for fostering co-operations, e.g. with the chemistry department..."

"..students... may have undergone somewhat harsher selection than students outside similar programs and have agreed to devoting time and effort to the framework program. Thus they have taken a decision for widening their horizons."...

".. this selection bias by the program makes the selected students those who will likely flourish in academia or the corporate sector BOTH due to the selection FOR the program AND due to the PROGRAM itself..."

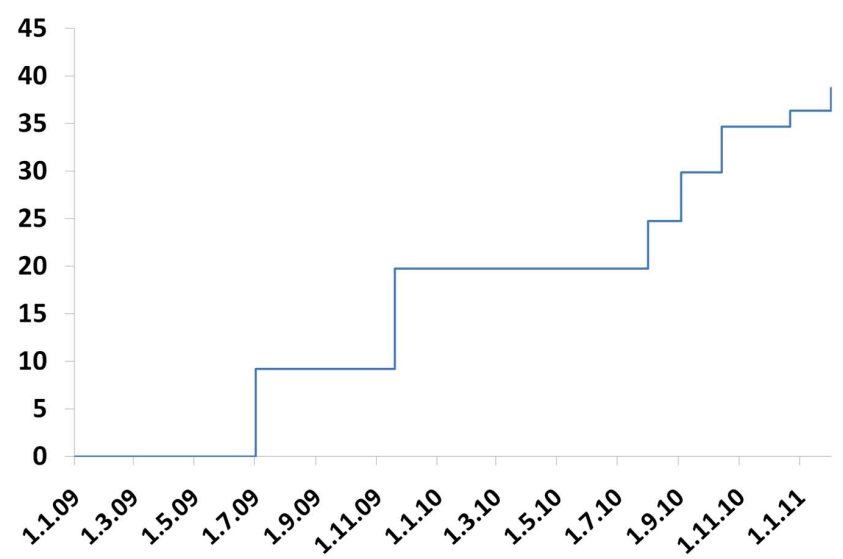

Fig. (3). Journal Impact Factor points involving program students over time.

As a preliminary approach to benchmark the structure of our program, some data were extracted from a recently published report of the National Academy of the United States investigating all US PhD-Programs [14]. The Boxand Whisker $\left(10^{\text {th }}\right.$ and $90^{\text {th }}$ percentile) plots show important predictors of educational and scientific productivity, regarding faculty and students. They were collected from a total of 118 pharmacology programs offered throughout the US. Projecting the respective numbers from our program, it becomes evident that our faculty is of a typical size, with a smaller than usual proportion of female faculty, but a larger than usual proportion of female students. Notably, research productivity - as gauged by annual number of peer-reviewed original publications - is above US average. Also, the proportion of principal investigators holding their own external funding is not low, taking into account the sizeable fraction from outside academia. The proportion of international students is in the lower range of expectation. Obviously, an educational success rate with regard to final completion rates cannot be predicted for our program at present. In this regard, however, one has to consider the fundamental differences of our 3-year program to the typical 5 -year (MSc-) PhD program in the United States, not just regarding time to graduation but also due to the fact that our students have successfully passed the diploma/masters level. It would be very worthwhile to compare our results with those of other programs which share our model of industry sponsorship and of a primarily educational goal. Although somewhat similar projects have been recently introduced 


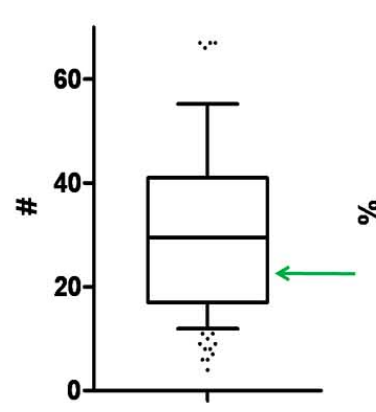

Faculty size

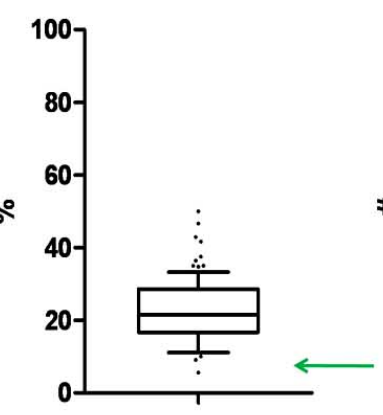

Female faculty

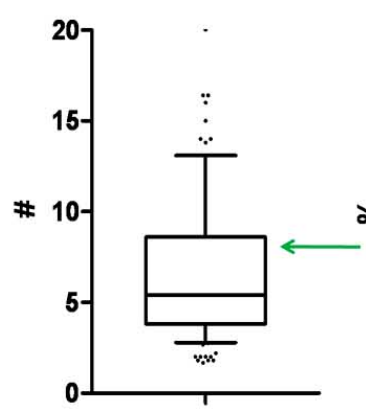

Student intake per year

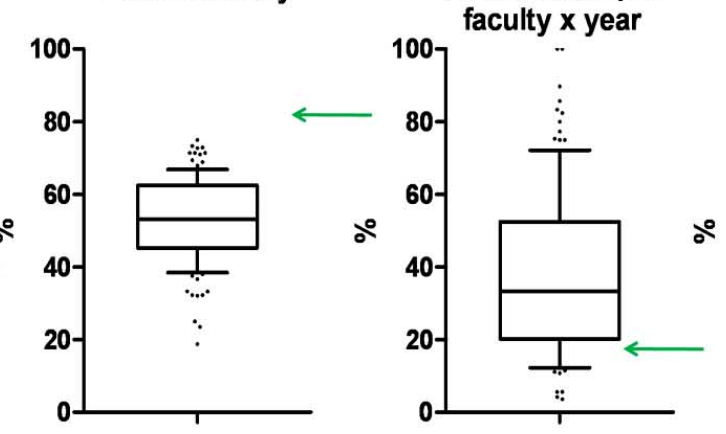

Female students

International students
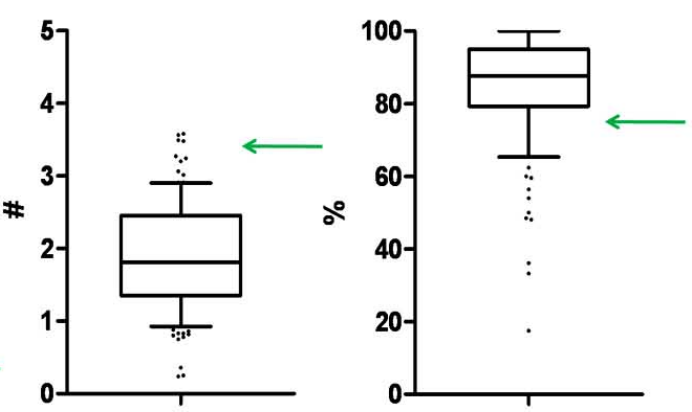

Faculty with grants

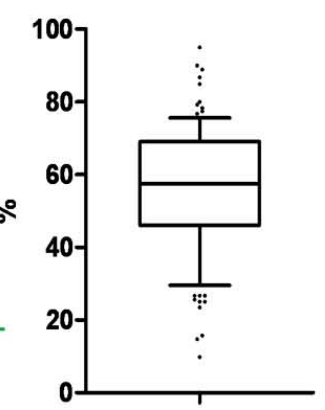

Graduation after 6 years

Fig. (4). Data [14] from 118 US PhD programs in pharmacology (box and whisker) compared to own program’s benchmarks (green arrows).

even in Germany, we have been unable so far to obtain the appropriate parameters.

\section{EXTERNAL EVALUATION}

Two external reviewers could be appointed, who hold distinguished academic positions outside Germany. As much of the paperwork and contract material preceding the establishment of the graduate program is in German we invited native German speakers as reviewers. (The graduate program itself strives to maintain all correspondence and educational activities in English). One of the reviewers is serving as a Vice Provost and Dean of Graduate Programs of a large-scale public university in the US, the other has a long record as Editor of one of the major Pharmacology journals. After having had access to all requested paper material they met with our program staff, students and faculty for two whole days at the occasion of our annual retreat in November 2010, including face-to-face interviews about the scientific, curricular and organizational aspects of the program. Immediately thereafter, they gave their ad hoc statements to the Steering committee of the privileged partnership. Below their main points of criticism and their recommendations are cited:

\section{Positive Statements}

"The added value for students is recognized. The program opens the professional field.

The exposure towards science is broader compared to a thesis done with an individual professor.
There is an intellectual community and interdisciplinary experience".

"The "journal club" was highly appreciated by all students I talked to."

\section{Criticisms and Recommendations}

"The program is thematically too heterogeneous. The common topical denominator of drug development has to be more strongly implemented into the curriculum, but not at the expense of a higher total teaching load."

"The students with a background in biochemistry or biology asked for more disciplinary coursework in pharmacology. They felt that going to "undergraduate" lectures did not make much sense. They would prefer graduate level courses or training (more custom-tailored to their needs).

The variety of doctoral degrees is confusing. There is a need for university-wide policies on (Ph.D.) degree clearance..."

"Student participation in future decisions regarding the program structure is desirable.

In addition to a mechanism that allows projects/students to be selected independently of their relevance to the Bayer portfolio, I would suggest that potential conflicts of interest of all participants are disclosed and reviewed ..." 
"There is a lack of sufficient transparency as to the role of the sponsor regarding maintenance of the curriculum versus the support of individual projects..."

\section{CONCLUSION}

With respect to our mission statement (Table 1) we may conclude that at least some of the important goals could be reached in quite a short time period. A structured, goaloriented curriculum was successfully implemented, although the emphasis on pharmacological topics has to be strengthened. Exposition to scientific role models was easy to facilitate and highly valued by our students. We have created a socially and scientifically fruitful climate of interdisciplinary and inter-institutional collaboration and begun to foster exchange between lab environments. This seems to hold great promise to create new ideas and synergies. The establishment of a translational research framework is only at its beginnings. Clearly the translational aspect has not been reached so far, perhaps due to the lack of clinical studies in our program. Finally to improve modern drug discovery a lot of effort will have to be devoted to improving connections not just between the partners but also to strengthening the relationships between the various disciplines within each institution. Transparency of the motivations and procedural mechanisms of industry funding [15] is a key demand for maintaining success.

\section{REFERENCES}

Brown, D. Target selection and pharma industry productivity: what can we learn from technology S-curve theory? Curr. Opin. Drug Discov. Devel., 2006, 9, 414-418.

[2] Lohse, M. The future of pharmacology. Trends Pharm. Sci., 1998, 19, 198-200.

[3] French, E.D. Academic pharmacologists: confronting new challenges in educational programs of graduate and health care professionals. J. Pharmacol. Exp. Ther., 2004, 309, 441-443
[4] Tallarida, R.J.; Stote, R.M.; Smith J.B.; Jacob, L.S. Academicindustrial cooperative graduate program in clinical pharmacology. J. Clin. Pharmacol., 1988, 28, 204-207.

[5] Meijer, D.K.F.; Wilting J. Trends in the organization of drug research: interfacing industry and universities. Eur. J. Pharm. Biopharm.,1997, 43, 243-252.

[6] Blumenthal, D; Causino, N; Campbell, E; Louis, K.S. Relationships between academic institutions and industry in the life sciences - an industry survey. N. Engl. J. Med., 1996, 334(6), 368373.

[7] Gourley, D.R.; Rowell, C.; Wingate, L.; Yates, C.R.; Gourley, G.K.; Miller, D.D.; Vleet, V. Status of PharmD/PhD programs in colleges of pharmacy: the University of Tennessee dual PharmD/PhD program. Am. J. Pharm. Educ., 2006, 70, 44.

[8] Gray, N.S. Drug discovery through industry-academic partnerships. Nat. Chem. Biol., 2006, 2, 649-653.

[9] Lessl, M.; Douglas, F. From technology transfer to know-how interchange. Wissenschaftsmanagement, 2010, 2, 34-41.

[10] Florida, R. The role of the university: Leveraging talent, not technology. Issues Sci. Technol., 1999, 15, 67-73.

[11] Harman, K. The Research Training Experiences of Doctoral Students Linked to Australian Cooperative Research Centres. Higher Education 2002, 44, 469-492.

[12] DFG (German Research Foundation): Guidelines and Proposal Preparation Instructions (Sample Proposal) for Proposals to Establish International Research Training Groups. http://www.dfg.de/download/programme/graduiertenkollegs/antrag stellung/1_301_e/1_301e.pdf (Accessed Feb 1 ${ }^{\text {st }}, 2011$ )

[13] Graduate School of Biological Sciences, University of Cologne, http://www.gs-biosciences.uni-koeln.de/gsfbs_start.html (Accessed Feb $1^{\text {st }}, 2011$ )

[14] Ostriker, J.P.; Kuh, C.V.; Voytuk, J.A., editors; Committee to Assess Research-Doctorate Programs; A Data-Based Assessment of Research-Doctorate Programs in the United States, National Research Council, 2010, http://www.nap.edu/rdp/ (Accessed Feb $1^{\text {st }}, 2011$ )

[15] Bekelman, J.E.; Li, Y; Gross C.P. Scope and impact of financial conflicts of interest in biomedical research: a systematic review. JAMA, 2003, 289, 454-465. 